\title{
Blood Donors Profile at the Blood Transfusion Regional Center Tulear, Madagascar
}

\author{
Irène Rakotoniana $\mathrm{A}^{1 *}$, Isabelle Ramandimbisoa $\mathrm{L}^{1}$, \\ Rasamindrakotroka $\mathrm{A}^{2}$ and Rakoto Alson $\mathrm{AO}^{3}$ \\ ${ }^{1}$ National Center for Blood Transfusion, Madagascar \\ ${ }^{2}$ Laboratory of Immunology Department, University Hospital HJRA, Madagascar \\ ${ }^{3}$ Laboratory of Hematology Department, University Hospital HJRA, Madagascar
}

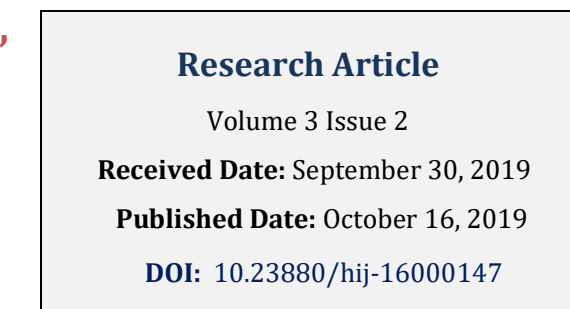

*Corresponding author: Andriamiarimbola Irène Rakotoniana, CHU Mitsijo Betanimena, BP: 356, Tuléar 602, Madagascar, Email: irenerakotoniaina2@yahoo.com

\section{Abstract}

Introduction: One way to find solution to blood donation insufficiency to establish the profile of donors. No study has been performed on blood donors at the regional blood center of Tulear. Our aim is to determine their profile and their exclusion patterns to develop an action plan.

Materials and Methods: The new regional blood center is working since five years. We analyzed all record of blood donors in the center between February and August 2015. The data was processed on EPI data 7.

Results: The male gender accounted for $83.7 \%$ of donors against $16.4 \%$ for female with an average age of 31 years. Family or replacement donors were $96.4 \%$. We excluded $21.5 \%$ of them during our study, because of low hemoglobin levels, health problems found during the donation, sexual risk behaviors, taking medications within 72 hours of donation, sexually transmitted diseases especially syphilis and non-compliance with the time interval between two blood donations respectively $11.5 \%, 6.5 \%, 1.6 \%, 0.8 \%, 0.5 \%, 0.3 \%$.

Conclusion: Donors were essentially donor replacements. They have been excluded because of their low hemoglobins levels.

Keywords: Blood Donors; Transfusion; Exclusion; South West Madagascar

\section{Introduction}

Blood transfusion is a medical act involving two main actors, donors and recipients. Donors may be volunteers, family or replacement. The donations of these last ones are destined to the needs of their family [1]. Donors take an important role in transfusion safety because they constitute a potential risk of transmitting infectious diseases to recipients. They must also be protected against possible adverse effects caused by donation that 
could affect their health, such as anemia [2]. Therefore they must meet certain criteria before being selected [3]. On the one hand the blood transfusion center ensures the safety of the recipients / donors and on the other hand it must address the problem of insufficient donation in relation to the demand for blood. To meet these responsibilities, our objective is to determine the profile of blood donors in the regional blood transfusion center in the southwest region of Madagascar and their reasons for exclusion.

\section{Materials and Methods}

We carried out a prospective descriptive transversal study within the Regional Center of Blood Transfusion of Tulear. We included all blood donors from October 2018 to April 2019 during which the dosage of hemoglobin was performed systematically. Each donor has a record consisting of a screening questionnaire, a result of the clinical examination at the time of donation, results screening tests for sexually transmitted infections such as HIV, HBV, HCV, or syphilis and the result of capillary haemoglobin levels. The parameters analyzed were gender, age, type of donor (volunteer donors or replacements), capillary haemoglobin level, results of the clinical examination selection criteria and the four serologies. The apparatus for the determination of hemoglobin was Hemo Control (EKF - diagnostic GmbH). The tests used for HIV, HBV, HCV and syphilis were rapid diagnostic tests, represented respectively by DETERMINE, HEPA-SCAN, flavicheck and RPR. The specificity for the DETERMINE, HEPA-SCAN, flavicheck and RPR test is respectively $99.87 \%, 99.37 \%, 99.5 \%, 99 \%$. The sensitivity for these four tests is $100 \%$ each. Donor exclusion criteria were hemoglobin less than or equal to $11 \mathrm{~g} / \mathrm{l}$ for both genders, risk behaviors, taking medication for 72 hours prior to donation, health problems present at the clinical examination and the positive serology at least to one of these four sexually transmitted infections. The data was analyzed on EPI info 7.

\section{Results}

We had 591 donors during our study period. Blood donors are represented mainly by male subjects with 83.7\% ( $\mathrm{n}=493$ ) versus $16.44 \%(\mathrm{n}=97)$ for female subjects. The sex ratio was 5.09. The average age was 31 years old. $65.7 \%(\mathrm{n}=388)$ of them were under 35 years old and $34.2 \%(\mathrm{n}=202)$ were between 36 and 60 years old. Volunteers accounted for $3.5 \%(n=21)$ of the donors and $96.4 \%(n=569)$ were replacement or family donors. After selection, $21.4 \%(\mathrm{n}=127)$ of donors were excluded, where $89 \%$ of whom were. The main reason for exclusion of these donors was low hemoglobin. These different exclusion factors are shown in Table 1.

\begin{tabular}{|c|c|c|}
\hline Exclusion reasons & Efficient & Percentage \\
\hline Low hemoglobin level & 68 & $11.5 \%$ \\
\hline $\begin{array}{c}\text { Health problem at the time of } \\
\text { donation }\end{array}$ & 39 & $6.5 \%$ \\
\hline Sexual behavior at risk & 10 & $1.6 \%$ \\
\hline Drug taken during the 72 hours & 5 & $0.8 \%$ \\
\hline Sexually transmitted infections & 3 & $0.5 \%$ \\
\hline Blood donations too close & 2 & $0.3 \%$ \\
\hline TOTAL & 127 & $21.4 \%$ \\
\hline
\end{tabular}

Table 1: The reasons for exclusion of blood donors.

Health problems at the time of donation were: hypotension, dermatitis, colds, abdominal pain, urinary tract infection, dental abscess, fever. Sexually transmitted infections are represented exclusively by a positive RPR test.

\section{Discussion}

The profiling of blood donors allows to develop or to re-evaluate the action plan within the blood center to address insufficient blood donation compared to the demand and to adhere the WHO strategies on blood donation. In our study, the prevalence of male gender among replacement donors is consistent with national data [4] as well as with other literature data [5]. By contrast, donor women were less numerous compared to other countries [6]. Physiological factors such as the menstrual cycle, pregnancy, breastfeeding favored women's abstinence from blood donation despite women being more generous and more willing than men [7]. In addition to these physiological factors, women also had much more post-donation reaction such as fatigue, vagal reactions, or hematoma at the point of collection [8] but we had none of these post-donation reactions. To exploit this generosity, sensitization should be carried out to educate them and explain them that these physiological factors should not prevent them from donating blood. Donors are mainly represented by a young population under 35 years of age, there were $65.7 \%$ at the national level [4] and in African countries [9]. There are any paid donors in the center and the pool of volunteer donors is still low compared to other countries [10] hence the WHO goal is not fully achieved [11]. Replacement donors accounted for $96.4 \%$ of donors, yet they are more likely to expose infectious risks [12], while voluntary donors provide transfusion safety [13]. 
After subjecting them to selection criteria, $21.4 \%$ were excluded in which $89 \%$ were temporarily excluded. The exclusion rate is high compared to other countries [14]. It is related to the high number of replacement donors in our study. The temporary exclusion makes difficult for these potential donors to return for another donation after a certain period [15]. These replacement donors were considered lost. In front of their importance, they should be sensitized to be part of the pool of volunteer donors. This awareness is also to inform them of the selection criteria so that they do not come to the center as long as they have one of these exclusion criteria.

The main reason for exclusion is variable, as it is in other countries, mainly hemoglobin [16]. This low level of hemoglobin is common to all populations in developing countries because they are prone to parasitic diseases, malnutrition but also to hematological diseases including sickle cell disease which are factors of decrease in the rate of hemoglobin [17]. This low hemoglobin level necessitated an extension of the donation sensitization theme such as systematic deworming and systematic screening for certain hematologic diseases responsible for chronic anemia.

For the analysis, we used a precise recommended device with good sensitivity and a low coefficient of variation to avoid the falsely low hemoglobin to limit the elimination of donors [18]. Our national blood transfusion policy has set donors with a hemoglobin level of $\geq 11 \mathrm{~g}$ / dl. If we kept the hemoglobin level of the donors according to the French Blood Establishment, our exclusion rate for low hemoglobin level would have doubled. The hemoglobin level $\geq 11 \mathrm{~g} / \mathrm{dl}$ is therefore justified for not to worsen the lack situation. Moreover, anemia only appears with a hemoglobin level of $9-10 \mathrm{~g} /$ $\mathrm{dl}$ in healthy people [19]. To reduce the risk of transmission of transfusion-transmissible infections, we have adopted blood quality control strategies using rapid diagnostic tests and strict selection of donors based on criteria established by the National Blood Transfusion Center and based on WHO recommendations [20]. From these criteria, we found that risk behavior was the third most important reason for excluding donors if for other authors it was in second place [16]. This variation may be related to the type of questionnaire applied in each transfusion center. With regard to transfusiontransmissible infections, the main infections found were syphilis, the seroprevalence of which was still low compared with other studies [21]. This may be related to the sensitivity of the reagent used for screening, which is
$100 \%$ or, at best, pre-test questionnaires that may already eliminate potentially infected donors.

\section{Conclusion}

The knowledge of the donors profile may partly explains the lack of blood in the transfusion center. It also makes possible to mention that the resolution of this problem is still a long-term task and concerns not only the health system but also and above all the economic system because the main reason for exclusion found was the low hemoglobin level especially related to the poverty of the population, in this case it would be necessary to improve the standard of living of the population in general. Since replacement donors were an infectious risk, it is important to increase awareness among youth and men to become volunteer donors, but also to awaken the generosity of women.

\section{References}

1. WHO (2007) Recommendations for the production, control and regulation of human plasma for fractionation.

2. Eder A, Goldman M, Rossmann S, Waxman D, Bianco C (2009) Selection criteria to protect the blood donor in North America and Europe: past (dogma), present (evidence), and future (hemovigilance). Transfus Med $\operatorname{Rev} 23(3):$ 205-220.

3. Karp JK, King KE (2010) International variation in volunteer whole blood donor eligibility criteria. Transfusion 50(2): 507-513.

4. Rakotoniaina AI, Randriamanantany ZA, Ranaivosoa KHM, Andriambelo V, Fortuné $H$, et al. (2013) Séroprévalence du VIH, VHB, VHC et de Treponema pallidumchez les donneurs du sang bénévoles au Centre National de Transfusion Sanguine d'Antananarivo de 1992 à 2010. Rev méd Madag 3(2): 264-268.

5. Nagalo MB, Sanou M, Bisseye C, Kaboré MI, Nebie YK, et al. (2011) Seroprevalence of human immunodeficiency virus, hepatitis $B$ and $C$ viruses and syphilis among blood donors in Koudougou (Burkina Faso) in 2009. Blood Transfus 9(4): 419-424.

6. Bani M, Giussani B (2010) Gender differences in giving blood: a review of the literature. Blood Transfus 8(4): 278-287. 
7. Tagny CT, Owusu-Ofori, Mbanya D, Deneys V (2010) The blood donor in sub-Saharan Africa: a review. Transfus Med 20(1): 1-10.

8. Newman BH, Pichette S, Pichette D, Dzaka E (2003) Adverse effects in blood donors after whole-blood donation: a study of 1000 blood donors interviewed 3 weeks after whole-blood donation. Transfusion 43(5): 598-603.

9. Nkrumah, Owusu M, Frempong HO, Averu P (2011) Hepatitis B and C Viral Infections among Blood Donors from Rural Ghana. Ghana Med J 45(3): 97100.

10. Fessehaye N, Naik D, Fessehaye T (2011) Transfusion transmitted infections. A retrospective analysis from the National Blood Transfusion Service in Eritrea. Pan Afr Med J 9: 40.

11. Ringwald J, Zimmermann R, Eckstein R (2010) Keys to open the door for blood donors to return. Transfus Med Rev 24(4): 295-304.

12. Charles KS, Hughes $P$, Gadd R, Bodkyn CJ, Rodriguez M (2010) Evaluation of blood donor deferral causes in the Trinidad and Tobago National Blood Transfusion Service. Transfus Med 20(1): 11-4.

13. Thornton JD, Wong KA, Cardenas V, Curtis JR, Spigner $C$, et al. (2006) Ethnic and gender differences in willingness among high school students to donate organs. J Adolesc Health 39(2): 266-274.

14. Kagu MB, Ahmed SG, Bashir MA, Malah MB, Usoro A, et al. (2010) Deferral patterns of voluntary blood donors at the National Blood Transfusion Service, North East Zonal Centre, Maiduguri. Afr J Med Med Sci 39: 119-125.

15. Custer B, Chinn A, Hirschler NV, Busch MP, Murphy EL (2007) The consequences of temporary deferral on future whole blood donation. Transfusion 47(8): 1514-1523.

16. Goncalez TT, Sabino EC, Schlumpf KS, Wright DJ, Mendrone A, et al. (2013) Analysis of donor deferral at three blood centers in Brazil. Transfusion 53(3): 531-538.

17. UNICEF (2005) Vers une approche intégrée pour un controle efficace de l'anémie. Déclaration conjointe de lOrganisation Mondiale de la santé et du fonds des Nations Unies pour l'enfance: focaliser surlanémie.

18. Bruce HD, Bart J (2010) International Council for Standardization in Haematologytechnical report 12009: new reference material forhaemiglobincyanide for use in standardization of bloodhaemoglobin measurements. Int Jnl Lab Hem 32(2): 139-141.

19. Cable RG (2003) Hb screening in blood donors: how close is close enough?. Transfusion 43(3): 306-308.

20. OMS (2010) Dépistage des infections transmissibles par transfusion dans les dons de sang: Recommandations.

21. Kaur G, Basu S, Kaur R, Kaur P, Garg S (2010) Patterns of infections among blood donors in a tertiary care centre: A retrospective study. Natl Med J India 23(3): 147-149. 